\title{
Precocious Puberty and Age Estimation: A Medico-Legal Case Report
}

\author{
Sanjeev Lalwani • Ashu Seith Bhalla $•$ Ajay Logani $\cdot$ S. Sharma
}

Received: 23 July 2013 / Accepted: 12 September 2013 /Published online: 15 November 2013

(C) Dr. K C Chaudhuri Foundation 2013

To the Editor: As per the Juvenile Justice (Care and Protection of Children) Rules 2007 of India, determination of age can be done by (i) the matriculation or equivalent certificates, (ii) the date of birth certificate from the school (other than a play school) first attended (iii) the birth certificate given by a corporation or a municipal authority or a panchayat and only in the absence of either of above, (iv) the medical opinion will be sought from a duly constituted medical board, which will declare the age of the juvenile or child.

While estimating the age of an individual multiple criteria's such as physical development, dental examination and radiological examination of appearance and fusion of epiphysis of long bones are commonly used. There has been considerable variation regarding the ages at which epiphyseal union occurs with diaphysis of individual bone. Variation could be seen depending on several factors [1].

A girl of low socioeconomic status and from illiterate family of rural background alleged to be of $13 \mathrm{y}$ of age was brought for bone age estimation in a case related to her abduction. Physical appearance of the girl was consistent with the age as alleged. Dental age was between 12-14 y (Second molar was present in all four quadrants). On radiological examination, iliac crest (19 y), medial end of clavicle (22 y) and multiple sternal

\section{S. Lalwani $(\bowtie)$}

Department of Forensic Medicine,

All India Institute of Medical Sciences, New Delhi 110029, India

e-mail: drsalal@rediffmail.com

\section{A. S. Bhalla}

Department of Radio-Diagnosis,

All India Institute of Medical Sciences, New Delhi, India

\section{A. Logani}

Centre for Dental Education \& Research,

All India Institute of Medical Sciences, New Delhi, India

\section{S. Sharma}

Department of Hospital Administration,

All India Institute of Medical Sciences, New Delhi, India ossification centres were found fused except 1 st and 2 nd sternbrae (puberty to $25 \mathrm{y}$ ). Therefore, the radiological bone age was found to be between 22-25 y. The discrepancy in the physical/dental age and the bone age was a serious medicolegal challenge. Endocrinology evaluation and ultrasonography did not reveal any significant finding.

History given by mother of the victim, revealed that the girl was born in 1998, admitted in the school directly in first standard in 2004, had first menses in 3rd standard (2006) suggestive of age at first menses to be about $8 \mathrm{y}$. Breast development also started simultaneously. Therefore, the diagnosis of precocious puberty was made.

Puberty is said to be precocious if breast budding begins before age 8 or menarche occurs before the age of 9 . Ninety percent cases of precocious puberty are of constitutional or idiopathic origin. In these, no cause of premature maturation of the central nervous system-hypothalamic-pituitary axis could be identified [2]. However, further clinical evaluation was suggested but patient did not turn up. Osseous maturation with earlier epiphyseal fusion and short height has been reported in such cases. Dental age and mental development are compatible with chronologic age [3]. This case highlights the importance of detailed history taking and physical developments in an individual while estimating the age of the person for law enforcement.

Conflict of Interest None.

Role of Funding Source None.

\section{References}

1. Reddy KSN. Identification. The Essentials of Forensic Medicine and Toxicology. Chapter-4. 25th ed. Hyderabad: K Suguna Devi; 2006. pp. 61-2.

2. Braunwald E, Fauci AS, Kasper DL, Hauser SL, Longo DL, Jameson JL. Harrison's Principles of Internal Medicine. 15th ed. USA: The McGraw Hill Companies; 2001. pp. 31-2, 2160.

3. Ghai OP. Essentials of Paediatrics. 4th ed. New Delhi: Interprint; 1996. pp. 378-9. 